\title{
Azobenzene-Based Gel Coated Fibre Bragg Grating Sensor for Moisture Measurement
}

\author{
Mohammed Moniruzzaman and John Rock \\ Centre for Defence Chemistry, Cranfield University, Defence Academy of the UK, Shrivenham, Swindon, Wiltshire SN6 8LA, UK \\ Correspondence should be addressed to Mohammed Moniruzzaman; m.moniruzzaman@cranfield.ac.uk
}

Received 17 February 2016; Revised 10 May 2016; Accepted 11 July 2016

Academic Editor: Chalongrat Daengngam

Copyright (C) 2016 M. Moniruzzaman and J. Rock. This is an open access article distributed under the Creative Commons Attribution License, which permits unrestricted use, distribution, and reproduction in any medium, provided the original work is properly cited.

\begin{abstract}
A fibre Bragg grating sensor is coated with a novel polymer gel in order to investigate its suitability for nondestructive measurement of moisture in materials that can potentially lose their integrity due to moisture ingress. Absorption and desorption of moisture lead to swelling/shrinkage of an azobenzene-based gel, which induces a strain in the Bragg grating resulting in wavelength shifts. The results demonstrated that the amount of wavelength shift is linearly dependent on the amount of water ingress by the gel. The performance of the proposed optical fibre moisture sensor was found to be repeatable with no detectable hysteresis and has the potential to offer a low-cost route for monitoring moisture content.
\end{abstract}

\section{Introduction}

The measurement of moisture is an important parameter in many applications such as structural health monitoring [1], agriculture [2], food quality assessment [3], and materials processing $[4,5]$. A wide variety of fibre optical humidity sensors have already been produced and can be divided broadly into (i) capacitive sensors in the form of interdigitated arrays, films, or probes $[2,6,7]$, (ii) electrical resistivity sensors in the form of probes or films [8,9], (iii) microwave sensors [10-12], and (iv) fibre optic Bragg sensors using polyimide coatings [13]. A majority of such sensors are based on electronics and measure changes in electron transduction due to humidity. Long-period gratings (LPGs) optical fibre-based humidity sensors have also been reported for condition monitoring of concrete during moisture ingress [14].

The diffusion of moisture in polymeric and fibre reinforced composite materials has been the subject of numerous studies, and this topic continues to attract considerable attention as absorbed moisture can compromise the mechanical performance of these materials [15]. For example, the diffusion of moisture can lower the glass transition temperature and also result in the degradation of the matrix-dominated properties such as the compressive and interlaminar shear strengths of composites. It is also generally known that the so-called hot-wet properties of this class of materials are also adversely affected.

Therefore, there is significant merit in designing and developing a low-cost sensor that can either be embedded or surface mounted in engineering structures to continually provide quantitative information on the moisture content and the diffusion profile within the materials.

Within the literature other researchers have reported on a number of optical fibre-based techniques for monitoring moisture content; these have been based on photosensitive coatings [16], evanescent wave spectroscopy, Fabry-Perot interferometry [17], and transduction to mechanical strain via swelling films [18]. Jindal et al. [16] used a blend of polyvinyl alcohol (PVA) and anhydrous cobalt chloride $\left(\mathrm{CoCl}_{2}\right)$ on the unclad region of a $200 \mu \mathrm{m}$ core diameter optical fibre for humidity detection via evanescent wave absorption [13]. The evanescent absorption was found to decrease with increasing humidity. In practice, it was found that a small radius of curvature was required in order to enhance sensitivity via stronger evanescent wave interaction. However, the response was found to be nonlinear with moisture content. Kharaz and Jones [19] adapted a distributed reflectometric optical fibre sensor system, a technique similar to that one developed by Jindal et al. [16]. The unclad region of $200 \mu \mathrm{m}$ core hard-clad silica (HCS) optical fibre was coated 
with a cobalt chloride- $\left(\mathrm{CoCl}_{2}{ }^{-}\right)$gelatin thin film. Gupta and Ratnanjali [20] reported a U-shape fibre optic humidity sensor based on phenol red doped polymethyl methacrylate film. They deposited a blend of the above materials over the unclad core of a highly multimode plastic clad silica fibre. The concentration of the dye dispersed in the film was reported to be $4.76 \% \mathrm{w} / \mathrm{w}$. They also reported that the absorption depends on the moisture present in the air around the film.

Bariáin et al. [18] reported an optical fibre humidity sensor based on the deposition of a biological gel called agarose on a biconically tapered monomode optical fibre (waist diameter of $25 \mu \mathrm{m}$ over a length of $100 \mu \mathrm{m}$ ). Absorption of moisture by the gel led to a change in the refractive index and this in turn altered the light guiding properties within the tapered region. The deployment of optical fibre-based Fabry-Perot cavities with moisture sensitive overlays was reported by Arregui et al. [17]. An interferometric cavity was formed due to different optical reflectivity of the alternating layers at the end of a cleaved fibre. The thickness of the overlay films increased with absorbed moisture via swelling and the hygroscopic nature of the coating resulted in an alteration of the reflectivity, the net effect being a change in the interference spectrum.

Hood et al. [21] reported that the use of a moisture sensor based on optical fibre coated with a superabsorbent polymer comprises a mixture of an acrylate resin and polyacrylamide. The superabsorbing polymer attracts moisture from the environment until an equilibrium is established. The use of fibre Bragg gratings (FBG) is extensive for sensing parameters such as temperature, pressure, and strain [22]. Cong et al. [23] reported on polyacrylamide coated FBG sensors for measuring salinity. Induced swelling and shrinking of a hydrophilic polymer induce mechanical strain on the FBG and this leads to a change in the peak reflection of the FBG. When the coated FBG was immersed in sodium chloride solutions of different concentrations, the peak reflection shifted towards the shorter wavelength but the reversibility was not reported. Yeo et al. [24] reported a fibre opticbased humidity sensors, fabricated using FBG coated with moisture sensitive polymer, that can detect and monitor the movement of moisture through standardized cubes made from samples of different types of structural concrete. They claimed that the optical fibre sensors reacted to the ingress of water migrated through the sample, indicated by a shift in the Bragg wavelength of the sensor.

Song et al. [25] developed a fibre Bragg grating (FBG) sensor based on a water swellable bead of sodium polyacrylate. The dry and swollen mass of the gel were found to be $0.019 \pm 0.003 \mathrm{~g}$ and $1.91 \pm 0.293 \mathrm{~g}$, respectively, indicating that the beads are able to carry an average of $1.89 \mathrm{~mL}$ of water $(1 \mathrm{~g} / \mathrm{mL})$. The sensor is reported to have good repeatability but is not completely free from hysteresis. Most recently Zheng et al. [26] developed a humidity sensor based on photonic crystal fibre (PCF) long-period grating (LPG) with high sensitivity and selectivity for nondestructive detection of moisture ingression into structures that can potentially lead to corrosion. The nanofilm-coated PCF-LPG sensor is selective to moisture in terms of resonance intensity change and wavelength shift. The nanofilms were deposited on the surface of interior air channels in the cladding of the PCFLPG. The authors suggested that the interior nanofilmcoated PCF-LPGs have a large resonance wavelength shift of $0.0007 \% / \mathrm{pm}$ within the $\mathrm{RH}$ region from $22 \%$ to $29 \%$. Previous research suggests that azobenzene-based polymers have the properties that can be tailored with the selection of specific acrylic monomers to generate a hydrophilic gel [27]. Most recently Zhang et al. [28] reported PMMA coated FBG sensor for water monitoring in jet fuel. Careful observation of their results suggests that the sensor shows great deal of hysteresis making it unsuitable for continuous moisture monitoring.

This paper reports on the fabrication of an FBG sensor using a custom-synthesized azobenzene-based polymeric gel and investigation of its strain behaviour in response to water absorption and desorption. The changes of strain and Bragg peak shifts as a function of water ingress by the gel are reported. The potential application of the sensor for moisture detection in various materials has also been discussed.

\section{Experimental Work}

2.1. Synthesis of Azobenzene-Based Acrylamide Gel. A polyacrylamide gel containing azobenzene chromophores in the side chain was synthesized by free-radical polymerization of acrylamide and trans-4-methacryloyloxyazobenzene [27] in presence of $\mathrm{N}, \mathrm{N}^{\prime}$-methylenebisacrylamide $(10 \%)$ as the cross-linker. Acrylamide (1.6 g, $22.5 \mathrm{mmol}), 2,2^{\prime}$-azobisisobutyronitrile $(100 \mathrm{mg})$, trans-4-methacryloyloxyazobenzene $(0.3 \mathrm{~g}, 1.128 \mathrm{mmol})$, and bisacrylamide $(190 \mathrm{mg})$ were dissolved in a mixture of tetrahydrofuran and water $(15 \mathrm{~mL}, 5: 1)$. The solution was stirred for 5 minutes and then poured into a reaction vessel. The polymerization reaction was carried out at $60^{\circ} \mathrm{C}$ for 82 hours. A transparent yellow gel was formed. The unreacted acrylamide and/or homopolymer of acrylamide were removed by firstly immersing in distilled water for two days followed by further two days in acetone. The gel was then dried in a vacuum oven at $70^{\circ} \mathrm{C}$ for 14 hours. The gel was characterised using mid-FTIR and solid-state NMR. The solid-state ${ }^{13} \mathrm{C}$ showed the presence of one unit of 4methacryloyloxyazobenzene per 100 acrylamide units. The characterisation of the gel is reported elsewhere [27].

2.2. Production of Gratings. The FBG used in this study was produced by the phase mask technique. The gratings were inscribed in a germanium doped core of a single mode $1550 \mathrm{~nm}$ optical fibre (Fibrecore, UK). The acrylate coating on the optical fibre was removed just prior to the inscription process; the coating was not reapplied. Hence, the diameter of the fibre within the sensing region prior to the application of the gel coating was $125 \mu \mathrm{m}$ thickness. Two Bragg grating sensors were used for these experiments with Bragg reflections at $1534.818 \mathrm{~nm}$ and $1534.762 \mathrm{~nm}$.

2.3. Coating the Fibre Bragg Gratings. The FBG was sandwiched between two layers of gel using the following technique: Firstly the FBG was aligned and secured onto a piece of aluminium foil with a window of dimensions $5 \times 1.5 \mathrm{~cm}$. 


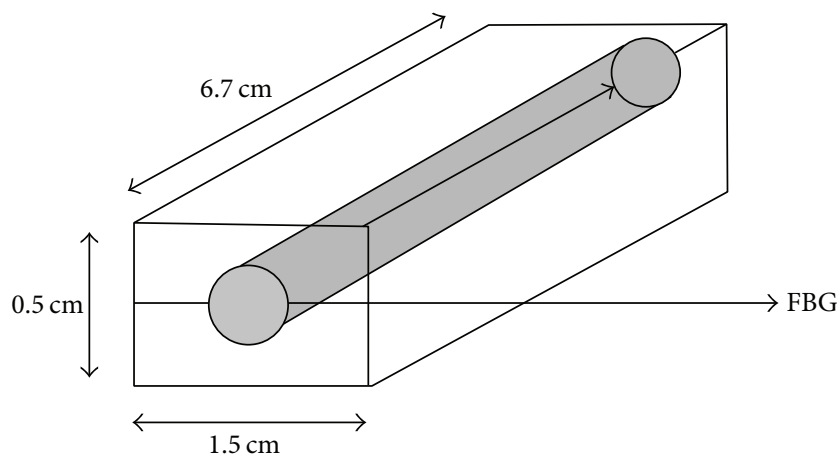

FIGURE 1: Schematic illustration of the FBG embedded in between two layers of gel.

A layer of gel was spread onto a glass slide and trimmed to rectangular dimensions of $6.7 \times 1.5 \times 0.25 \mathrm{~cm}$. The FBG was aligned along the centre of the coating. The FBG was under a slight tension during this process to avoid buckling. Another layer of gel, trimmed in the same manner, was positioned symmetrically above the FBG. Then the gel coating on Bragg grating was allowed to dry at room temperature $\left(23^{\circ} \mathrm{C}\right)$ for 15 hours so that two layers stuck to the Bragg grating region. The coated region was again soaked with water. A schematic illustration of the coating is shown in Figure 1.

A Fourier transform infrared spectrometer (Nicolet Magna-IR 760) operating with a quartz beam splitter was used to collect the near-infrared transmission spectrum of the FBG. The light was coupled into one end of the fibre and the output was collected using an InGaAs detector. The spectra were recorded at a resolution of $0.14 \mathrm{~nm}$. The transmission spectra of the FBG were recorded before embedding it in the gel. The FBG was coated with the gel as described previously. The transmission spectra were recorded at a resolution of $0.14 \mathrm{~nm}$. The coated FBG was then placed on a microbalance and the percentage weight change and the wavelength shifts were monitored simultaneously.

\section{Results and Discussion}

An azobenzene-based gel was synthesized by free-radical polymerization in $\mathrm{THF} / \mathrm{H}_{2} \mathrm{O}$ at $60^{\circ} \mathrm{C}$ with a yield of approximately $60 \%$. The reaction scheme is shown in Figure 2.

Water was added to keep the low-molecular-weight crosslinked gel in solution to facilitate further cross-linking. The purity of the gel was ascertained with mid-FTIR and solidstate ${ }^{13} \mathrm{C}$ NMR spectroscopy and has been reported [27]. With reference to the solubility of the monomers and the gel, acrylamide and bisacrylamide were soluble in water, but the azobenzene monomer and its copolymer were insoluble. The gel was not soluble in acetone or THF, which are solvents for trans-methycryloyloxyazobenzene and its homopolymer. When the gel was allowed to soak in distilled water for 2 or 3 weeks, the supernatant water became pale yellow, presumably because the ester linkage undergoes slow hydrolysis resulting in the formation of some 4-hydroxyazobenzene, which is sparingly soluble in water. The loading of azobenzene in the polyacrylamide fraction was around $4 \mathrm{~mol} \%$. The novelty of using the azobenzene chromophores in the gel is that azobenzene creates free volume due to its bulky nature resulting in a fast response.

To determine the response times of the system, water saturated gel was coated around the FBG which showed a peak reflection at $1534.762 \mathrm{~nm}$. Subsequently the gel on the sensor was allowed to dry at room temperature $\left(23^{\circ} \mathrm{C}\right)$ and characteristic reflection frequency of the coated FBG was monitored periodically. No change was observed in the characteristic reflection of FBG until after 36 hours of isothermal drying at $23^{\circ} \mathrm{C}$. This behaviour was expected as the gel was fully saturated with water and would take prolonged time to loose enough water to be able to generate an adhesion force on the Bragg grating at such a low temperature $\left(23^{\circ} \mathrm{C}\right)$. Upon further drying the characteristic reflection at $1534.818 \mathrm{~nm}$ shifted to $1529.386 \mathrm{~nm}$ within 4 hours at room temperature. The shift towards the shorter wavelength is shown in Figure 3. It should be noted that this is only illustrative in terms of the gel response to moisture and does not reflect a slow response time as the sensor will have a dried gel coating and hence be under a generated strain, and that this will change as a function of water content.

The response time of the dried gel was measured by immersion in distilled water at $23^{\circ} \mathrm{C}$ until the transmission spectrum of the FBG peak reflection was restored to its original value of $1534.818 \mathrm{~nm}$ which took around 11 minutes.

In a separate experiment the gel was isothermally dried at $23^{\circ} \mathrm{C}$ during which both the weight loss and the strain developed in the gel were monitored. Then the gel was allowed to absorb water from a chamber containing saturated sodium chloride solution and the shift in the Bragg peak due to release of strain was measured periodically; see Figure 4.

It is clearly shown in Figure 4 that the wavelength of the Bragg peaks shifted towards longer wavelength due to ingress of water in the gel. Similar peaks shift towards longer wavelength region was observed by Venugopalan et al. when LPG sensors were coated with PVA polymer and subjected to absorb moisture by increasing the relative humidity from 33 to $75 \%$ [14].

The relationships between the loss or gain of moisture, wavelength shifts, and strain are shown in Figure 5. The graph can be explained by the strain increasing linearly with the loss of water and vice versa; and simultaneously the wavelength of the Bragg peak changes. It is observed that the Bragg wavelength of 1534.762 was shifted to $1534.306 \mathrm{~nm}$ with a weight loss of $12.64 \%$ as shown in Figure 5. This finding demonstrates that there is a definitive relationship among the loss of water from the gel coated on the Bragg grating sensor, its associated strain, and consequently the Bragg wavelength shift.

The weight loss curve (Figure 5) shows linear behaviour. The values of water loss, wavelength shift, and strain are calculated using (1), (2), and (3) and listed in Table 1. Note that a very small amount of water loss from the coated gel generated a large amount of strain with associated Bragg peak reflection.

When the gel coating was again immersed in water ( $\sim 110$ minutes), the Bragg wavelength returned to its original 


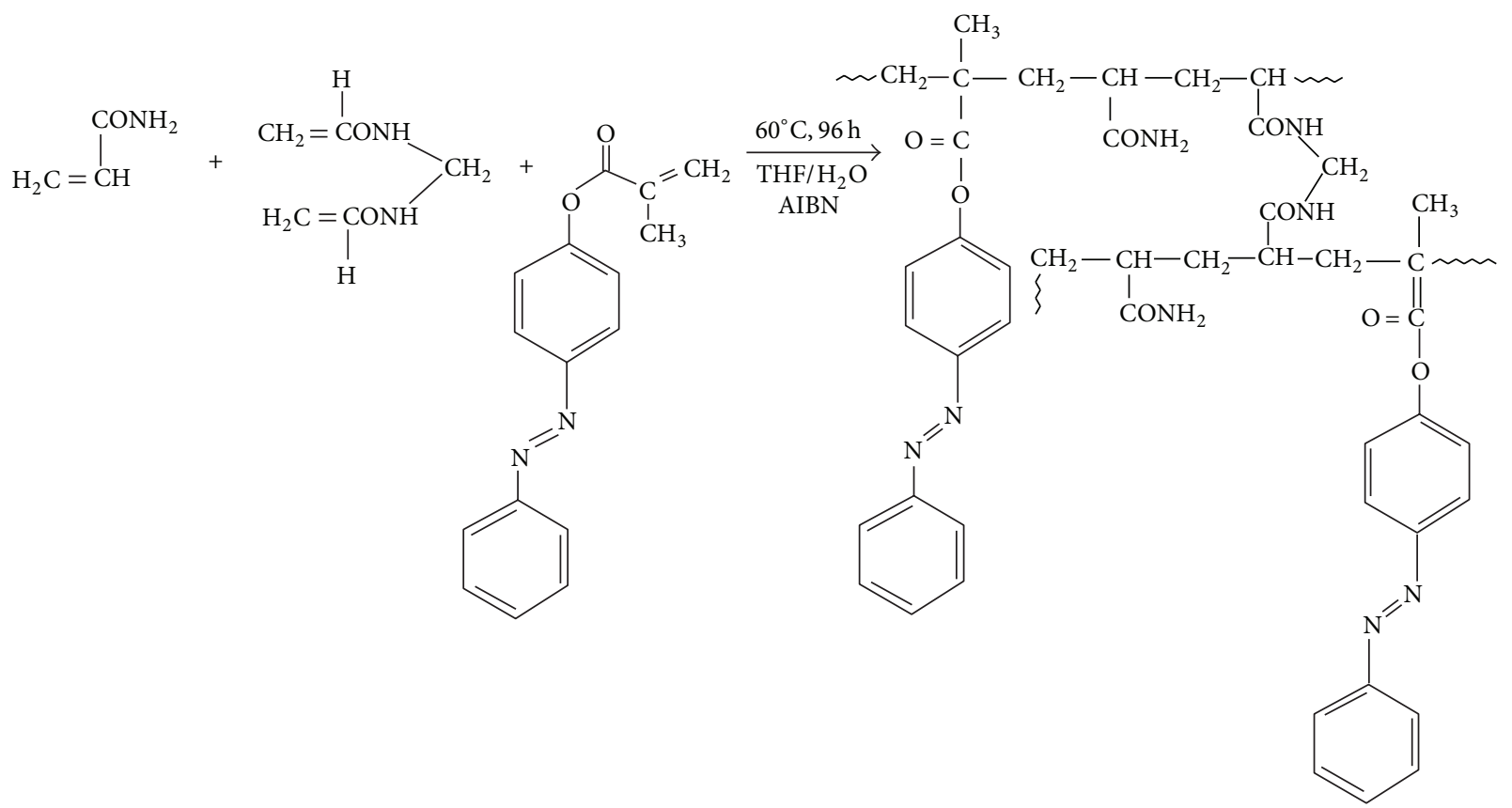

FIGURE 2: Reaction scheme for the synthesis of the polyacrylamide/azobenzene gel.

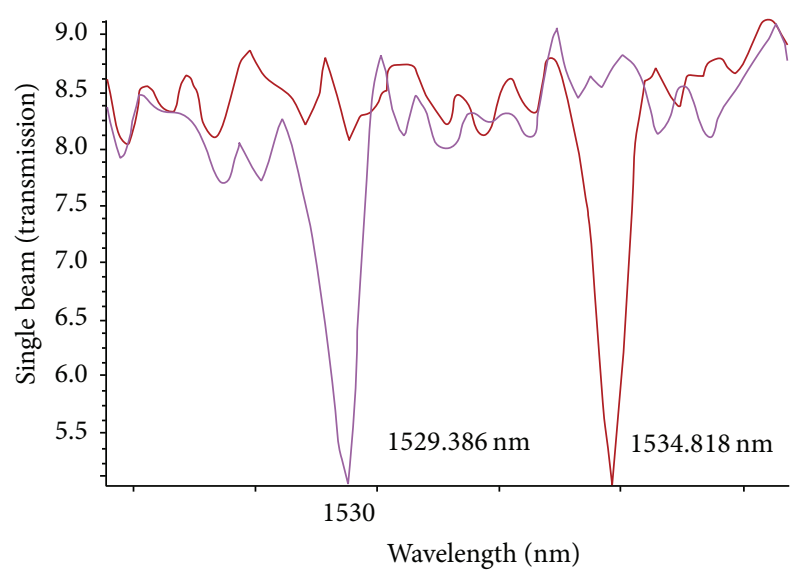

FIGURE 3: Bragg wavelength shift due to drying of gel.

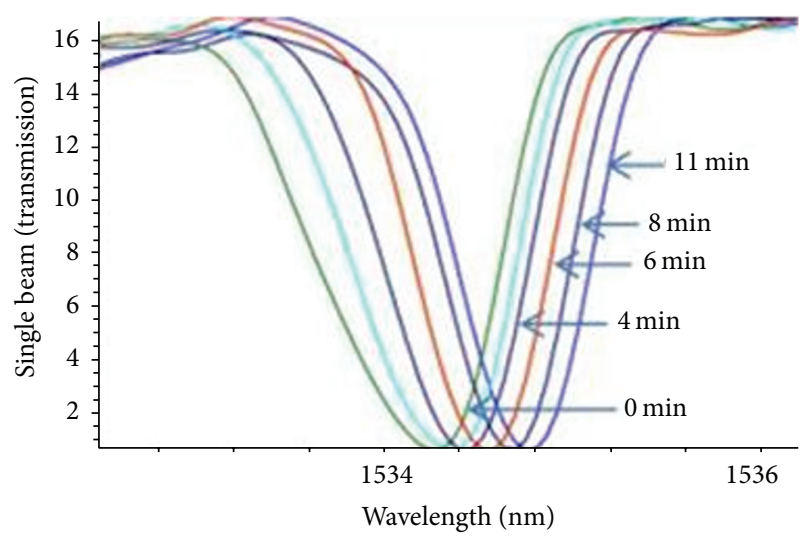

FIGURE 4: Bragg wavelength shifts as a function of time of water ingress.

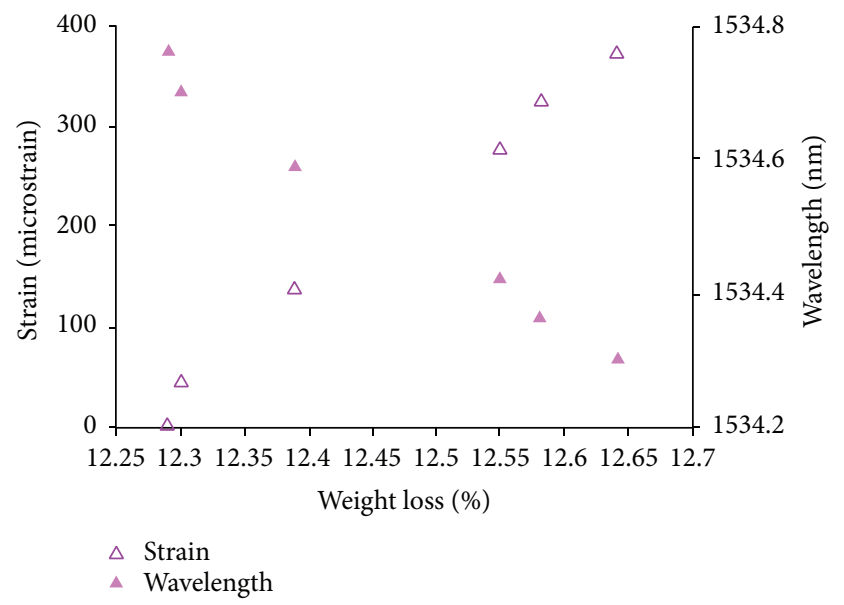

FIGURE 5: A plot of strain and wavelength against weight loss of gel.

value of $1534.762 \mathrm{~nm}$ indicating that the response of FBG was hysteresis-free. From the repeatability test the gel, even when saturated with water, showed good adhesion to the FBG and can undergo many swelling and contracting cycles without degradation.

Drying of the gel generated longitudinal compressive strain on the FBG and thus reduced the grating period. So the characteristic reflection of the FBG shifts towards a shorter wavelength. Consider the following:

$$
\lambda_{\text {Bragg }}=2 n_{\mathrm{eff}} \cdot \Lambda_{\mathrm{Bragg}}
$$

where $n_{\text {eff }}$ is the effective refractive index of the fibre core, $\Lambda_{\text {Bragg }}$ is the grating spacing, and $\lambda_{\text {Bragg }}$ is the Bragg peak 


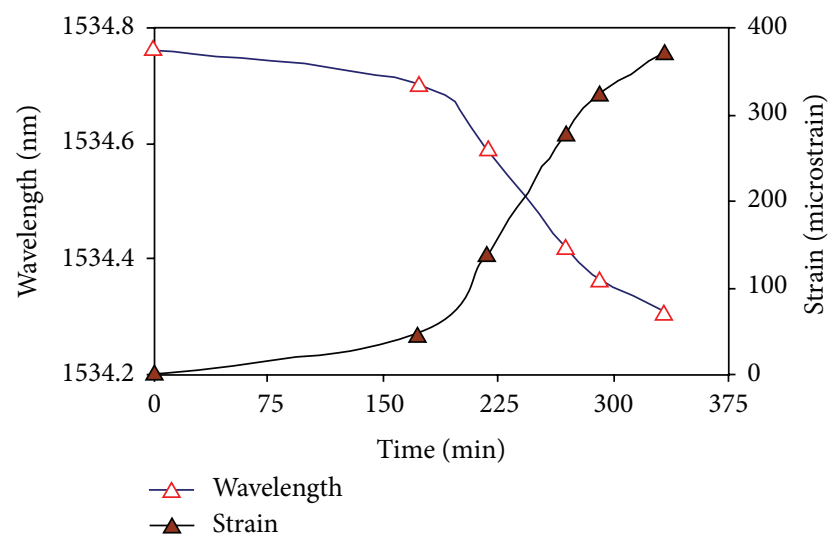

Figure 6: Temporal variation of Bragg wavelength and induced strain.

TABLE 1: Values of water, strain, and Bragg reflections.

\begin{tabular}{lcc}
\hline Water loss $(\%)$ & Strain $(\mu \varepsilon)$ & Peak reflection $(\mathrm{nm})$ \\
\hline 12.65 & 110 & 1534.78 \\
12.55 & 140 & 1534.68 \\
12.37 & 260 & 1534.58 \\
12.30 & 340 & 1534.30 \\
12.27 & 380 & 1534.20 \\
\hline
\end{tabular}

wavelength. The shift $\Delta \lambda_{\text {Bragg }}$ in peak wavelength of FBG due to a longitudinal strain $\varepsilon_{z}$ is expressed as

$$
\Delta \lambda_{\text {Bragg }}=\lambda_{\text {Bragg }}\left(1-p_{e}\right) \varepsilon_{z},
$$

where $p_{e}$ is the effective strain optic constant. The effective strain optic constant is expressed as

$$
p_{e}=\left(\frac{n_{\mathrm{eff}}^{2}}{2}\right)\left(\rho_{12}-v\right)\left(\rho_{11}+\rho_{12}\right),
$$

where $\rho_{11}$ and $\rho_{12}$ are the components of strain optic tensor and $v$ is Poisson's ratio. For a germanosilicate core, $\rho_{11}=$ $0.113, \rho_{12}=0.252$, and $v=0.16$ [29]. The effective refractive index of the core of FBG employed for this experiment is 1.447 and a grating spacing is $530 \mathrm{~nm}$. The effective strain optic constant is calculated and used in (2) to obtain $\Delta \lambda_{\text {Bragg. }}$.

The temporal variation of wavelengths and strains due to drying/soaking of the gel with time is shown in Figure 6. It is shown that the strain generation with associated wavelength shifts is very slow until about 150 minutes; after this time the rate of strain generation is much faster as is also the change in wavelength. This trend is as expected as a saturated gel takes a much longer time to dry out at a lower temperature $\left(23^{\circ} \mathrm{C}\right)$. The response of the sensor is much faster and linear in the region (Figure 6) where the gel has already produced some strain.

The linear behaviour of the strain release due to water ingress is shown in Figure 7. When the sensor with dried gel was allowed to absorb water the strain started to be released with an associated shift in wavelength. The amount of wavelength shift corresponds to the amount of water in the

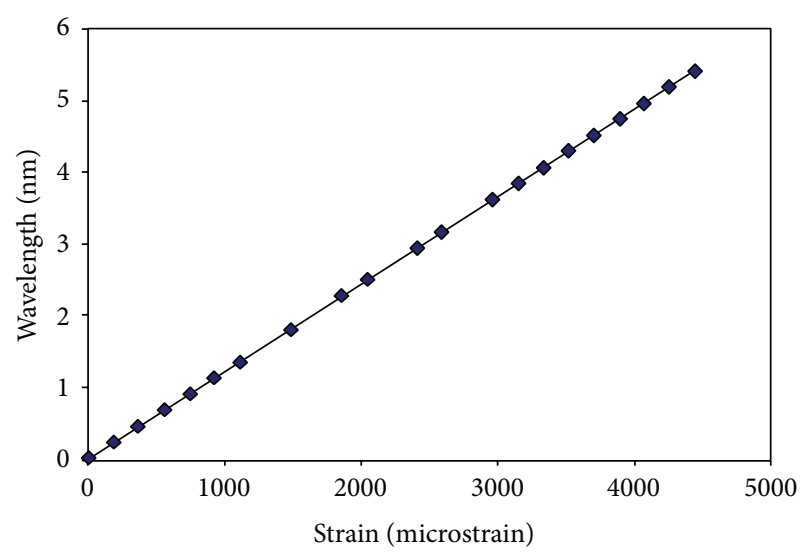

FIGURE 7: Wavelength shifts as a function of strain release.

gel on the sensor (see Table 1). This behaviour is linear until the gel reached near saturation point; then the strain becomes nonlinear.

The wavelength shift of $5.432 \mathrm{~nm}$ (see Figure 3) was used in (3) to calculate the strain value which corresponds to $4438 \mu \varepsilon$. When the gel swells, it changes its volume which is due to the imbalance between the water activity inside the gel and that of its surroundings; this imbalance creates an osmotic pressure between the two regions until thermodynamic equilibrium is restored. The forces inside the gel which affect the pressure internally are the rubber elasticity of the gel (which produces a force that promotes swelling in a dried gel and shrinkage in a swollen gel), the polymer-polymer affinity (positive for a dried gel), and the polymer-water affinity [30]. The polymer gel surrounding the FBG shrinks on the surface of FBG along its length. Therefore the shrinking of gel around the FBG is envisioned as compressive stress along the length of the fibre. The induced wavelength shifts due to swelling/shrinkage of gel are treated as longitudinal stress relaxation/growth.

A change in temperature of the fibre will also affect the Bragg spacing and is equivalent to $0.01 \mathrm{~nm}^{\circ} \mathrm{C}^{-1}$. Compared to that induced by the swelling of the gel its effect is negligible.

In operation the gel reacts to changes in water concentration with water either diffusing into or out of the gel resulting in a concentration gradient and consequently a stress gradient throughout the thickness of the gel. This limits the speed of reaction of the sensor and is equal to the time it takes for the gel to equilibrate $\left(t_{1 / 2}=7 \mathrm{~min}\right)$ [27]. At equilibrium conditions the concentration of water within the gel is constant and so is the developed strain in the sensor. Only under these conditions can the sensor accurately determine the water concentration. However before these conditions are reached, the sensor is still able to indicate changes in the surrounding environment. The observation that the strain transferred to the FBG when the sensor is immersed in distilled water shows that there is still good interfacial adhesion between the fully hydrated gel and the glass interface. 


\section{Conclusions}

We have synthesized an azobenzene-based acrylamide gel that was coated onto an optical fibre Bragg grating and have shown that this can be used to determine moisture content. The experimental results have demonstrated that induced wavelength shifts of a FBG due to swelling and shrinkage of polyacrylamide-azobenzene gel are a function of its water content when it has reached the equilibrium. The sensor was constructed by using a fully saturated gel which is subsequently dried; this induced a compressive strain in the Bragg grating. Absorption of water by the gel results in a reduction of the induced compressive strain in the grating, which is measured by a shift in the Bragg peak. The response time of the sensor could be further improved by producing a thinner coating on the FBG together with a modification of the chemistry of the gel to enhance the diffusion of water. The performance of the FBG-based moisture sensor was found to be repeatable without any hysteresis and has the potential to develop a low-cost sensor for nondestructive monitoring of moisture in materials.

\section{Competing Interests}

The authors declare that they have no competing interests.

\section{Acknowledgments}

The authors would like to thank Dr. Venkata Rajnikanth Machavaram for his assistance and discussion during this work.

\section{References}

[1] A. Singhvi and A. Mirmiran, "Creep and durability of environmentally conditioned FRP-RC beams using fiber optic sensors," Journal of Reinforced Plastics and Composites, vol. 21, no. 4, pp. 351-373, 2002.

[2] H. Eller and A. Denoth, "A capacitive soil moisture sensor," Journal of Hydrology, vol. 185, no. 1-4, pp. 137-146, 1996.

[3] J. F. Frank and G. S. Birth, "Application of near infrared reflectance spectroscopy to cheese analysis," Journal of Dairy Science, vol. 65, no. 7, pp. 1110-1116, 1982.

[4] A. Singhvi, Creep and Durability of FRP-RC Beams under Sustained Loads and in Harsh Environments Using Fibre-Optic Instrumentation, University of Cincinnati, Cincinnati, Ohio, USA, 2000.

[5] A. P. Mathew, S. Packirisamy, M. G. Kumaran, and S. Thomas, "Transport of styrene monomer through natural rubber," Polymer, vol. 36, no. 26, pp. 4935-4942, 1995.

[6] N. Inagaki, K. Oh-ishi, and K. Suzuki, "Capacitive moisture sensor devices from plasma films," Journal of Applied Polymer Science, vol. 31, no. 8, pp. 2473-2481, 1986.

[7] N. Inagaki, K. Suzuki, and K. Oh-Ishi, "Moisture sensor devices composed of thin films plasma-polymerized from aminogroups-containing silanes," Applied Surface Science, vol. 24, no. 2, pp. 163-172, 1985.

[8] N. A. Gawande, D. R. Reinhart, P. A. Thomas, P. T. McCreanor, and T. G. Townsend, "Municipal solid waste in situ moisture content measurement using an electrical resistance sensor," Waste Management, vol. 23, no. 7, pp. 667-674, 2003.

[9] G. O. I. Ezeike, "A resistive probe moisture sensor for tropical root crops and vegetables," Journal of Agricultural Engineering Research, vol. 37, no. 1, pp. 15-26, 1987.

[10] S. Nakayama, "Development of a microwave moisture sensor for aggregates," Measurement Science and Technology, vol. 6, no. 4, pp. 429-431, 1995.

[11] M. P. Abegaonkar, R. N. Karekar, and R. C. Aiyer, "A microwave microstrip ring resonator as a moisture sensor for biomaterials: application to wheat grains," Measurement Science and Technology, vol. 10, no. 3, pp. 195-200, 1999.

[12] M. P. Abegaonkar, R. N. Karekar, and R. C. Aiyer, "A microwave microstrip ring resonator as a moisture sensor for biomaterials: application to wheat grains," Review of Scientific Instruments, vol. 7, pp. 3145-3149, 1999.

[13] T. L. Yeo, T. Sun, K. T. V. Grattan, D. Parry, R. Lade, and B. D. Powell, "Characterisation of a polymer-coated fibre Bragg grating sensor for relative humidity sensing," Sensors and Actuators, B: Chemical, vol. 110, no. 1, pp. 148-156, 2005.

[14] T. Venugopalan, T. Sun, and K. T. V. Grattan, "Long-period grating-based humidity sensor for potential structural health monitoring," Sensors and Actuators A: Physical, vol. 148, no. 1, pp. 57-62, 2008.

[15] C. R. Kurkjian, J. T. Krause, and M. J. Matthewson, "Strength and fatigue of silica optical fibers," Journal of Lightwave Technology, vol. 7, no. 9, pp. 1360-1370, 1989.

[16] R. Jindal, S. Tao, J. P. Singh, and P. S. Gaikwad, "High dynamic range fiber optic relative humidity sensor," Optical Engineering, vol. 41, no. 5, pp. 1093-1096, 2002.

[17] F. J. Arregui, Y. Liu, I. R. Matias, and R. O. Claus, "Optical fiber humidity sensor using a nano Fabry-Perot cavity formed by the ionic self-assembly method," Sensors and Actuators B: Chemical, vol. 59, no. 1, pp. 54-59, 1999.

[18] C. Bariáin, I. R. Matías, F. J. Arregui, and M. L. Amo, “Optical fiber humidity sensor based on a tapered fiber coated with agarose gel," Sensors and Actuators B: Chemical, vol. 69, no. 12, pp. 127-131, 2000.

[19] A. Kharaz and B. E. Jones, "A distributed optical-fibre sensing system for multi-point humidity measurement," Sensors and Actuators A: Physical, vol. 47, no. 1-3, pp. 491-493, 1995.

[20] B. D. Gupta and Ratnanjali, "A novel probe for a fiber optic humidity sensor," Sensors and Actuators B: Chemical, vol. 80, no. 2, pp. 132-135, 2001.

[21] P. J. Hood, C. M. Theodore, and A. M. Yates, "Fibre optic moisture sensor," US patent No 6,582,658 BI, 2003.

[22] A. D. Kersey, M. A. Davis, H. J. Patrick et al., "Fiber grating sensors," Journal of Lightwave Technology, vol. 15, no. 8, pp. 1442-1463, 1997.

[23] J. Cong, X. Zhang, K. Chen, and J. Xu, "Fiber optic Bragg grating sensor based on hydrogels for measuring salinity," Sensors and Actuators B: Chemical, vol. 87, no. 3, pp. 487-490, 2002.

[24] T. L. Yeo, M. A. C. Cox, L. F. Boswell, T. Sun, and K. T. V. Grattan, "Optical fiber sensors for monitoring ingress of moisture in structural concrete," Review of Scientific Instruments, vol. 77, no. 5, Article ID 055108, 2006.

[25] G. Song, S. Gangbing, S. C. M. Ho, and R. Liang, "Fibre Bragg grating systems and methods for moisture detection," US patent No 20140102190A1, April 2014. 
[26] S. Zheng, Y. Zhu, and S. Krishnaswamy, "Fiber humidity sensors with high sensitivity and selectivity based on interior nanofilmcoated photonic crystal fiber long-period gratings," Sensors and Actuators B: Chemical, vol. 176, pp. 264-274, 2013.

[27] M. Moniruzzaman, G. F. Fernando, and J. D. R. Talbot, "Synthesis and characterization of an azobenzene- and acrylamidebased photoresponsive copolymer and gel," Journal of Polymer Science, Part A: Polymer Chemistry, vol. 42, no. 12, pp. 28862896, 2004.

[28] C. Zhang, X. Chen, D. J. Webb, and G.-D. Peng, "Water detection in jet fuel using a polymer optical fibre Bragg grating," in 20th International Conference on Optical Fibre Sensors, 750380, vol. 7503 of Proceedings of SPIE, October 2009.

[29] K. K. Andreas Othonos, Fibre Bragg Gratings, Artech House, Norwood, Mass, USA, 2009.

[30] T. Tanaka, “Gels," Scientific American, vol. 244, no. 1, pp. 124138, 1981. 

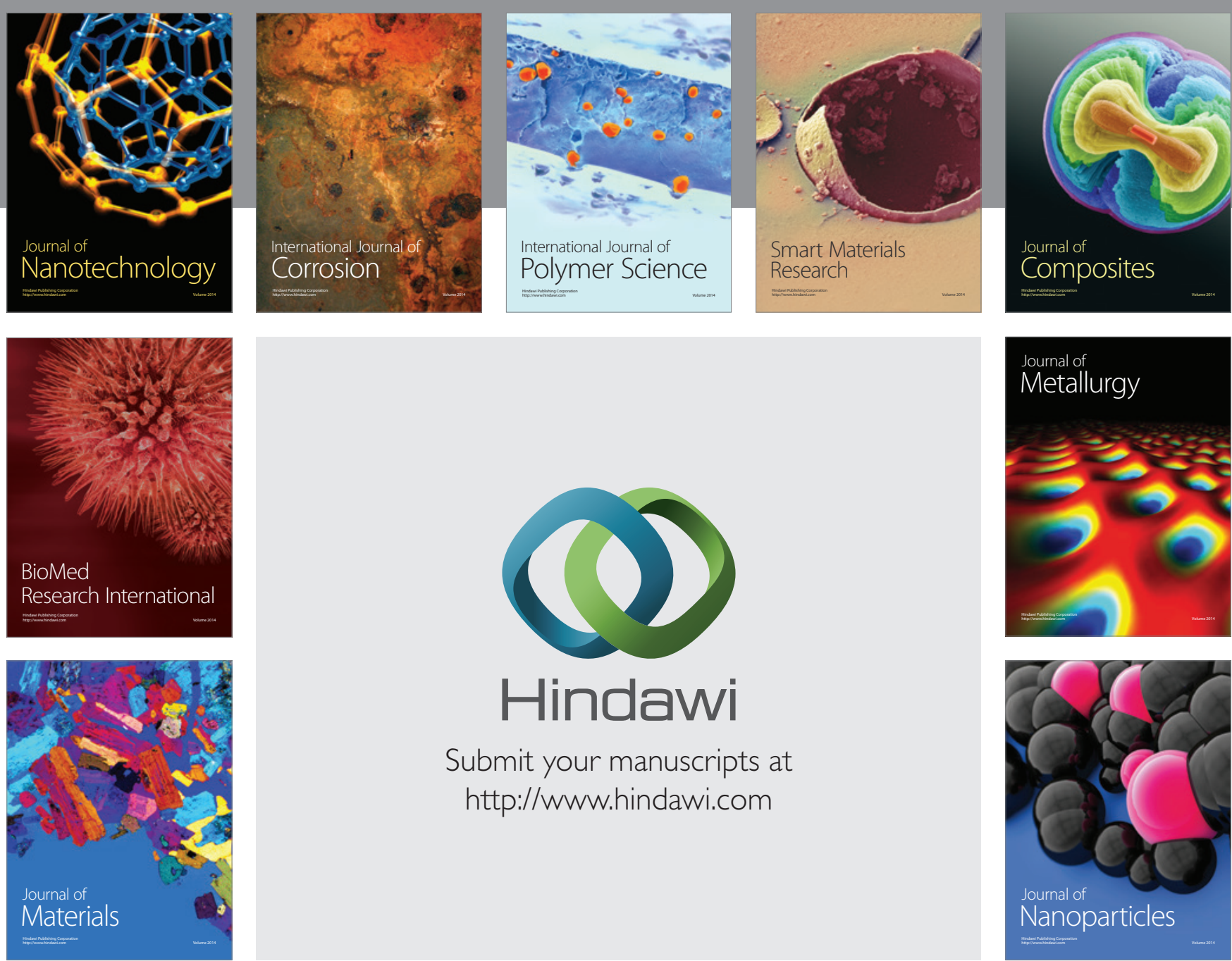

\section{Hindawi}

Submit your manuscripts at

http://www.hindawi.com

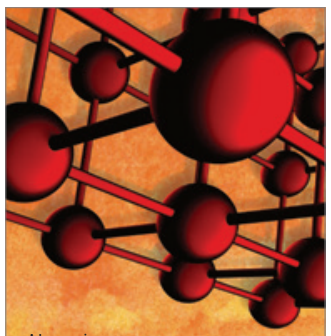

Materials Science and Engineering
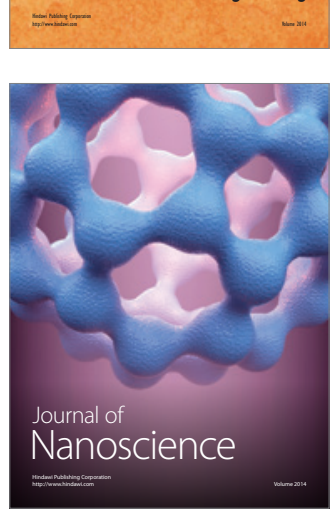
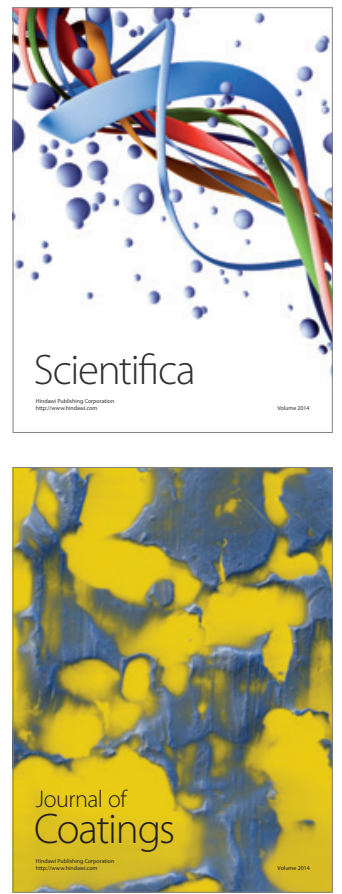
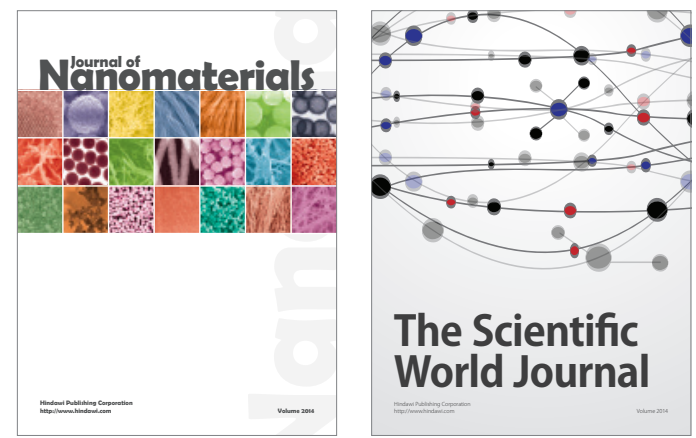

The Scientific World Journal
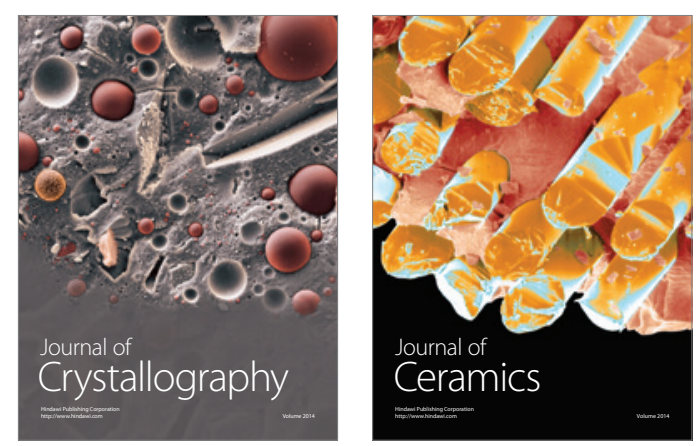
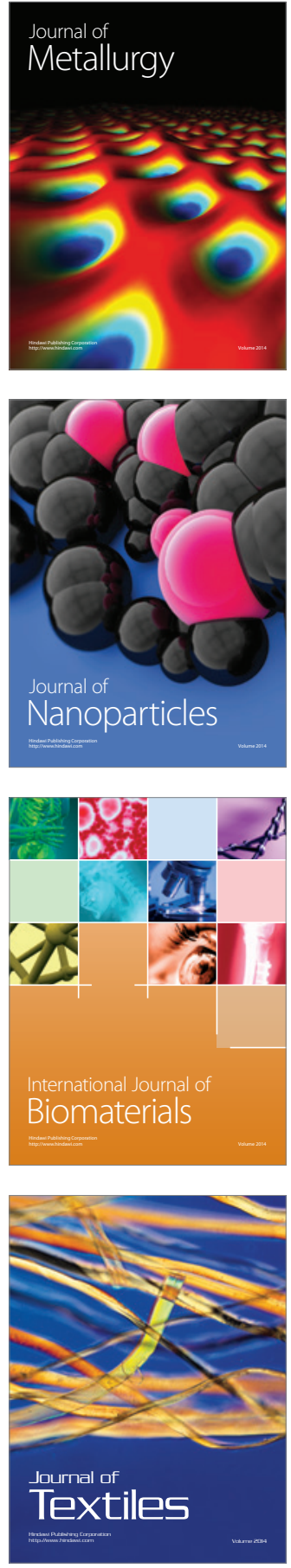